\title{
Exposure of Aspergillus flavus NRRL 3357 to the Environmental Toxin, 2,3,7,8-Tetrachlorinated Dibenzo-p-Dioxin, Results in a Hyper Aflatoxicogenic Phenotype: A Possible Role for Caleosin/Peroxygenase (AfPXG)
}

\author{
Abdulsamie Hanano*, Ibrahem Almousally and Mouhnad Shaban \\ Department of Molecular Biology and Biotechnology, Atomic Energy Commission of Syria, Damascus, Syria
}

OPEN ACCESS

Edited by:

Masoomeh Shams-Ghahfarokhi, Tarbiat Modares University, Iran

Reviewed by:

Kunlong Yang

Jiangsu Normal University, China

Shihua Wang,

Fujian Agriculture and Forestry

University, China

*Correspondence:

Abdulsamie Hanano

ascientific@aec.org.sy

Specialty section:

This article was submitted to

Food Microbiology,

a section of the journal

Frontiers in Microbiology

Received: 20 August 2019 Accepted: 25 September 2019

Published: 15 October 2019

Citation:

Hanano A, Almousally I and

Shaban M (2019) Exposure

of Aspergillus flavus NRRL 3357

to the Environmental Toxin,

2,3,7,8-Tetrachlorinated

Dibenzo-p-Dioxin, Results in a Hyper

Aflatoxicogenic Phenotype:

A Possible Role

for Caleosin/Peroxygenase (AfPXG).

Front. Microbiol. 10:2338.

doi: 10.3389/fmicb.2019.02338
Aflatoxins (AFs) as potent food contaminants are highly detrimental to human and animal health. The production of such biological toxins is influenced by environmental factors including pollutants, such as dioxins. Here, we report the biological feedback of an active AF-producer strain of $A$. flavus upon in vitro exposure to the most toxic congener of dioxins, the 2,3,7,8-tetrachlorinated dibenzo-p-dioxin (TCDD). The phenotype of TCDDexposed $A$. flavus was typified by a severe limitation in vegetative growth, activation of conidia formation and a significant boost in AF production. Furthermore, the level of reactive oxygen species (ROS) in fungal protoplast was increased (3.1- to 3.8fold) in response to TCDD exposure at 10 and $50 \mathrm{ng} \mathrm{mL}^{-1}$, respectively. In parallel, superoxide dismutase (SOD) and catalase (CAT) activities were, respectively, increased by a factor of 2 and 3 . In contrast to controls, transcript, protein and enzymatic activity of caleosin/peroxygenase (AfPXG) was also significantly induced in TCDD-exposed fungi. Subsequently, fungal cells accumulated fivefold more lipid droplets (LDs) than controls. Moreover, the TCDD-exposed fungi exhibited twofold higher levels of $\mathrm{AFB}_{1}$. Interestingly, TCDD-induced hyperaflatoxicogenicity was drastically abolished in the AfPXG-silencing strain of $A$. flavus, suggesting a role for AfPXG in fungal response to TCDD. Finally, TCDD-exposed fungi showed an increased in vitro virulence in terms of sporulation and AF production. The data highlight the possible effects of dioxin on aflatoxicogenicity of A. flavus and suggest therefore that attention should be paid in particular to the potential consequences of climate change on global food safety.

Keywords: dioxin, aflatoxicogenicity, aflatoxin, caleosin, peroxygenase

\section{INTRODUCTION}

Aflatoxins (AFs) are fungal lipid-derived toxins that provoke both acute and chronic toxicity in humans and animals. These toxins are produced by certain ascomycete fungi, most notably Aspergillus flavus and Aspergillus parasiticus (Yu et al., 2004; Shephard, 2008; Yu, 2012) and contaminate a range of fresh and stored food/feed products, therefore causing serious health, 
economic and ecological troubles. Thus, AFs were evaluated by the International Agency for Research on Cancer (IARC) as Group-1 agents (IARC, 2002). Of these, aflatoxin $B_{1}\left(A_{F} B_{1}\right)$ is considered as the most potent carcinogen contaminant identified to date, with hepatocellular carcinoma as a major risk factor (Yu et al., 2004; Yu, 2012).

From an ecological point of view, A. flavus is widely spread in different niches where environmental factors play crucial roles in the phenotyping of fungal aflatoxicogenicity. More particularly, fungal spores have a remarkable connection with soil where its physicochemical and biological properties are determinant modulators of conidia biogenesis. Interestingly, increasing attention has been recently paid to the possible adverse effects caused by climate change in connection with fungal aggressivity (Medina et al., 2014; Assuncao et al., 2018). As a possible consequence of climate change, persistent environmental pollutants could dramatically increase because of the increased incidence of large-scale forest fires that has occurred over the last decade. Such pollutants, namely polychlorinated dibenzo-p-dioxins (PCDDs) and polychlorinated dibenzofurans (PCDFs), are considered the most toxic group of Persistent Organic Pollutants (POPs) (WHO, 2016). Due to their physicochemical properties, dioxins can persist in the environment and bioaccumulate in the organisms of a given ecosystem, including bacteria, fungi, plants, animals, and humans (Field and Sierra-Alvarez, 2008; Ishida et al., 2010; Anasonye et al., 2014; Hanano et al., 2014b).

The cytotoxicity of dioxins is expressed through their high lipophilicity which exercises a force driving on dioxins toward the cellular lipids, affecting therefore their metabolism and functions (Lawrence and Kerkvliet, 1998; Hanano et al., 2014a,b, 2018b; Cranmer-Byng et al., 2015). In connection with this, dioxininduced alternations in lipid metabolism and oxidative status could have important feedback effects on the biology of AFproducing fungi in general and on their aflatoxicogenicity in particular. This is because aflatoxins are ultimately synthesized from acetyl-CoA via fatty acid polyketide under an excessive oxidative status (Reverberi et al., 2010; Fountain et al., 2018; Kenne et al., 2018). Beyond the modulatory role of reactive oxygen species (ROS), fungal lipids and their metabolites, more particularly a class of them know as oxylipins, can play as modulators of AF biosynthesis (Roze et al., 2007; Gao and Kolomiets, 2009; Fountain et al., 2014). The fungal oxylipin-biosynthesizing enzyme, the AfPXG, has been recently characterized as a caleosin with a peroxygenase activity and therefore referred to as Caleosin/Peroxygenase (Hanano et al., 2015). This AfPXG is necessary for fungal growth, development and AF production (Hanano et al., 2015). More recently, we presented detailed genetic, molecular and biochemical evidence on the direct implication of AfPXG in the biosynthesis of aflatoxins and their trafficking and extracellular secretion via lipid droplets (LDs) (Hanano et al., 2018a). A similar implication of fungal LDs in the sequestration and trafficking of lipid-soluble molecules has been also suggested in plants. The LDs isolated from oilseeds or date palm stones can sequester in vitro a variety of hydrophobic organic contaminants, with the greatest activity found for dioxins (Boucher et al., 2008; Hanano et al., 2016a).
Likewise, the dioxin-sequestration activity of LDs was also demonstrated in planta, where the majority of experimentally administrated dioxins to Arabidopsis or date palm seedlings was found within LD fractions (Hanano et al., 2016b, 2018b). This high activity was based on the production of numerous small LDs, and this ensures the highest contact surface between the LDs and the dioxins (Hanano et al., 2016b, 2018b,c).

Based on the above, hydrophobic pollutants could have significant effects on the biology of AF-producing fungi and subsequently on their aflatoxicogenicity. To that end, we in vitro exposed the A. flavus NRRL 3357 to 2,3,7,8-tetrachloronated dibenzo-p-dioxin (TCDD), the most toxic congener of the dioxins group. Then, the toxicological effects of dioxins were characterized in terms of fungal growth, development and aflatoxin production. In a particular connection with the TCDDinduced accumulation of LDs, the transcripts and enzymatic activity of the caleosin/peroxygenase AfPXG were discussed using the wild-type (WT) and the AfPXG-silenced lines of A. flavus. Finally, the virulence of the TCDD-exposed A. flavus was assayed. This work highlights the biological effects on the aflatoxicogenicity of $A$. flavus following its exposure to the persistent environmental pollutant, the dioxin.

\section{MATERIALS AND METHODS}

\section{Materials, Chemicals, Strains, Culture Conditions, and Treatments}

Oligonucleotides were purchased from either Eurofins or SigmaFrance. Aniline, cumene hydroperoxide, aflatoxin $\mathrm{AFB}_{1}$ and all organic solvents were purchased from Sigma-Aldrich, Germany. The A. flavus strain NRRL3357 was supplied from the Faculty of Agricultural Sciences, Gembloux, Belgium. Stock cultures of A. flavus were maintained in slant tubes at $4^{\circ} \mathrm{C}$ on potato dextrose agar (PDA) (Difco Laboratories, United States). For solid or liquid cultures of $A$. flavus, stock cultures were transferred onto Petri dishes containing PDA or into a 500-mL Erlenmeyer flask containing $100 \mathrm{~mL}$ of $\mathrm{PD}$ broth and kept for 7 days at $28^{\circ} \mathrm{C}$.

\section{Biomass and Conidia Number Measurements}

Fungal biomass, expressed as dry weight per plate, was measured as previously described (Hanano et al., 2015). In parallel, the total conidia fraction for each plate was harvested and taken up in $5 \mathrm{ml}$ solution of $0.01 \%$ Tween 80 , diluted to $1: 10$, and counted using a hemocytometer.

\section{Preparation of $A$. flavus LDs Fraction and Peroxygenase Activities Assay}

Isolation of fungal LD fractions was performed essentially as described by Ferreira de Oliveira and co-workers (Record et al., 1998; Ferreira De Oliveira et al., 2010) with brief modification as described previously (Hanano et al., 2015). In brief, $5 \mathrm{~g}$ of fungal mycelium was ground into a mortar in the presence of liquid nitrogen until a fine powder was obtained. The dried powder was immediately hydrated with $10 \mathrm{~mL}$ of buffer A (100 mM potassium 
pyrophosphate, $0.1 \mathrm{M}$ sucrose and $\mathrm{pH} 7.4$ ). The mixture was then gently homogenized for $5 \mathrm{~min}$ using an ultra-dispenser (T25 digital ULTRA-TURRAX, IKA laboratory, Germany) and centrifuged for $10 \mathrm{~min}$ at $10,000 \times \mathrm{g}$. The resulting supernatant was centrifuged at $100,000 \times g$ for $1 \mathrm{~h}$, and this enabled the obtainment of a floating white pad layer consisting of LDs. LDs were gently collected from the top of the tube using a Pasteur pipette, then carefully washed twice with $5 \mathrm{~mL}$ of buffer B (buffer A without sucrose). After a final centrifugation $(100,000 \times g$ for $1 \mathrm{~h}$ ), the LD fraction was suspended in $1 \mathrm{~mL}$ of buffer $\mathrm{B}$ and stored at $4^{\circ} \mathrm{C}$ for further analysis. Peroxygenase activity was assayed by oxygenation of aniline as a substrate (Blee and Durst, 1987; Hanano et al., 2006).

\section{Analysis of LDs}

Microscopic imaging was performed at a magnification of $40 \times$ under a LEICA MPS60 microscope using an Olympus FE-4000 camera. The purity of LD preparation, their native encapsulation and their number per $\mathrm{mL}$ were evaluated under a LEICA MPS60 light microscope, and the images were taken at a magnification of $40 \times$ immediately after preparation.

\section{SDS-PAGE and Western Blotting}

Lipid droplet-associated proteins were isolated according to Katavic et al. (2006) and analyzed by SDS-PAGE using $12 \%$ polyacrylamide gels and electroblotted onto a PVDF membrane (Millipore) in a Semi-Dry Transfer Cell (Bio-Rad). Caleosins were immunodetected by incubating the membrane with a polyclonal antibody prepared from the complete sequence of the CLO1 caleosin isoform from Arabidopsis thaliana, as described previously (Hanano et al., 2018c).

\section{Genes, Primers and Transcript Analysis}

Nucleotide sequences of primers used in this section are listed in Table 1. For the gene expression studies, A. flavus was grown as described previously. Total fungal biomass was collected for total RNA isolation using an RNeasy kit according to the manufacturer's instructions (Qiagen, Germany). DNA traces were removed by 2 units of RNase-free RQI DNase (Promega, United States) for $1 \mathrm{~h}$ at $37^{\circ} \mathrm{C}$. RNAs were diluted to $50 \mathrm{ng} \mathrm{\mu L}^{-1}$ using RNase-free water and stored at $-80^{\circ} \mathrm{C}$. cDNA synthesis was performed using M-MLV RT (Invitrogen) as described previously (Hanano et al., 2015). Real-time PCR was carried out in 96-well plates using an AriaMx Real-time PCR System from Agilent technologies, United States. The $25-\mu l$ reaction mixtures contained $0.5 \mathrm{mM}$ of each target and reference gene primers, $12.5 \mu \mathrm{l}$ of SYBR Green qRT-PCR mix (Bio-Rad, United States) and $2.5 \mu \mathrm{l}$ of 10 -fold diluted cDNA. qRT-PCR conditions were as previously described (Hanano et al., 2015). Each point was triplicated and the average of $C_{T}$ was taken. The relative quantification $\mathrm{RQ}=2^{(-\Delta \Delta C T)}$ of the target gene was calculated.

\section{Extraction, Clean-Up, TLC and HPLC Analysis of Aflatoxin}

The extraction of AF was done according to Bertuzzi et al. (2011) using $50 \mathrm{~mL}$ of chloroform for $1 \mathrm{~h}$ on a rotary-shaker,
TABLE 1 | Primers used for the transcriptional analysis of AF-biosynthesis cluster genes.

\begin{tabular}{|c|c|c|c|c|}
\hline Gene & $\begin{array}{l}\text { Primers } \\
\text { name }\end{array}$ & Nucleotide sequence $\left(5^{\prime}-3^{\prime}\right)$ & $\begin{array}{l}\text { Primer } \\
\text { position }\end{array}$ & $\begin{array}{l}\text { Amplicon } \\
\text { (bp) }\end{array}$ \\
\hline fas-a & $\begin{array}{l}\text { fasaF } \\
\text { fasaR }\end{array}$ & $\begin{array}{l}\text { CAACGCCAACGCTATTCGAG } \\
\text { GTAATGCCACACGATTCGGC }\end{array}$ & $\begin{array}{l}537-556 \\
697-716\end{array}$ & 180 \\
\hline fas- $b$ & $\begin{array}{l}\text { fasbF } \\
\text { fasbR }\end{array}$ & $\begin{array}{l}\text { ATCCACTCGACATCATCGCC } \\
\text { TTGATGTCACGTCGGCTGAA }\end{array}$ & $\begin{array}{l}2468-2487 \\
2563-2582\end{array}$ & 115 \\
\hline pksA & $\begin{array}{l}p k s A F \\
p k s A R\end{array}$ & $\begin{array}{l}\text { TAGTGTGCCTCTGCCAGTTG } \\
\text { GGAACCCATGCAGAATCCCA }\end{array}$ & $\begin{array}{l}254-273 \\
341-360\end{array}$ & 107 \\
\hline nor-1 & $\begin{array}{l}\text { nor1F } \\
\text { nor1R }\end{array}$ & $\begin{array}{l}\text { GCATCGGACGAGGTCTCATT } \\
\text { CTGGGCATCAGTITCCGAGT }\end{array}$ & $\begin{array}{l}158-177 \\
308-327\end{array}$ & 170 \\
\hline norA & $\begin{array}{l}\text { norAF } \\
\text { norAR }\end{array}$ & $\begin{array}{l}\text { TTGGTACTGAGCGAGGAGGA } \\
\text { TTCTAGCCGAGTGTTGCAGG }\end{array}$ & $\begin{array}{c}940-959 \\
1079-1098\end{array}$ & 159 \\
\hline avnA & $\begin{array}{l}\operatorname{avnAF} \\
\operatorname{avnAR}\end{array}$ & $\begin{array}{l}\text { ATCGACGACTGTTGGCCTाT } \\
\text { CGAGTCTCCAAAAGCGAGGT }\end{array}$ & $\begin{array}{l}386-405 \\
554-573\end{array}$ & 188 \\
\hline adhA & $\begin{array}{l}\text { adhAF } \\
\text { adhAR }\end{array}$ & $\begin{array}{l}\text { TCTAGAGACGGGGCAGAACA } \\
\text { TGCAAAGGAGACACCTGCAA }\end{array}$ & $\begin{array}{l}147-166 \\
299-318\end{array}$ & 172 \\
\hline $\operatorname{avfA}$ & $\begin{array}{l}\text { avfAF } \\
\operatorname{avfAR}\end{array}$ & $\begin{array}{l}\text { AGTACCGGCCTTCGTTCATC } \\
\text { AGTCTGTAGCCCGTTGGTTG }\end{array}$ & $\begin{array}{l}411-430 \\
568-587\end{array}$ & 177 \\
\hline estA & $\begin{array}{l}\text { estAF } \\
\text { estAR }\end{array}$ & $\begin{array}{l}\text { ACGCTACGAGATGATGCCAG } \\
\text { TCCCCCGAAGAAAGTCCTCT }\end{array}$ & $\begin{array}{l}766-785 \\
896-915\end{array}$ & 150 \\
\hline$v b s$ & $\begin{array}{l}v b s F \\
v b s R\end{array}$ & $\begin{array}{l}\text { CCGCTCTGATGACTCCCTTC } \\
\text { GTCCGATGCAACAATCTCGC }\end{array}$ & $\begin{array}{l}1509-1528 \\
1647-1666\end{array}$ & 158 \\
\hline verb & $\begin{array}{l}\text { verbF } \\
\text { verbR }\end{array}$ & $\begin{array}{l}\text { GATGCTCAATAACGCTGCCG } \\
\text { GTAAGGTACGGCAGATGCGA }\end{array}$ & $\begin{array}{c}963-982 \\
1129-1148\end{array}$ & 186 \\
\hline ver-1 & $\begin{array}{l}\operatorname{ver1F} \\
\operatorname{ver1R}\end{array}$ & $\begin{array}{l}\text { TGGTGAACTACGCCCATTCC } \\
\text { CACCGTCTCCGCCATTAACT }\end{array}$ & $\begin{array}{l}110-129 \\
227-246\end{array}$ & 137 \\
\hline verA & $\begin{array}{l}\text { verAF } \\
\text { verAR }\end{array}$ & $\begin{array}{l}\text { CCTCAGCAGCCACCCAAATA } \\
\text { CCGCCACTTCTTCCAAGTCT }\end{array}$ & $\begin{array}{l}290-309 \\
398-417\end{array}$ & 128 \\
\hline omtB & $\begin{array}{l}\text { omtBF } \\
\text { omtBR }\end{array}$ & $\begin{array}{l}\text { GCAAACGGCAAATTCAGGGT } \\
\text { CGCTAGAGTTATCGGCGTGT }\end{array}$ & $\begin{array}{c}71-90 \\
224-243\end{array}$ & 173 \\
\hline omtA & $\begin{array}{l}\text { omtAF } \\
\text { omtAR }\end{array}$ & $\begin{array}{l}\text { ATGTGACGAAGTGATGCGGT } \\
\text { CTCGCATTTCAGCTGCGTTC }\end{array}$ & $\begin{array}{l}294-313 \\
430-449\end{array}$ & 156 \\
\hline ordA & $\begin{array}{l}\operatorname{ord} A F \\
\operatorname{ord} A R\end{array}$ & $\begin{array}{l}\text { ATाTGTGTTCGGCTाTGGGC } \\
\text { TGGGCGAGATGAAGAAGCAG }\end{array}$ & $\begin{array}{c}1524-1543 \\
1611-163\end{array}$ & 107 \\
\hline apa-2 & $\begin{array}{l}\text { ара2F } \\
\text { apa2R }\end{array}$ & $\begin{array}{l}\text { CGCTATTGCTGCTITCGCT } \\
\text { GCATCGGTAGCCCTCTTGTT }\end{array}$ & $\begin{array}{l}691-710 \\
829-848\end{array}$ & 158 \\
\hline$T E^{\mathrm{a}}$ & $\begin{array}{l}\text { TEF } \\
\text { TER }\end{array}$ & $\begin{array}{l}\text { AGGCTITCTITGTGAGCCGT } \\
\text { ATAGCTGATGCTGACGGAGC }\end{array}$ & $\begin{array}{l}357-376 \\
469-488\end{array}$ & 132 \\
\hline
\end{tabular}

a TE - Transcriptional Enhancer encoding gene.

and extracts were purified as described previously (Shannon et al., 1983). The extracted AF samples were analyzed by thin layer chromatography (TLC) using a $\mathrm{C}_{18}$ reversed-phase TLC plate (aluminum sheets measuring $20 \times 20 \mathrm{~cm}$ with $200-\mu \mathrm{m}$ layers, Merck, Germany) and the chromatogram was developed using a solvent system of chloroform/acetone (90:10, v/v). After development, the spot with the same $R f$-value as the $\mathrm{AFB}_{1}$ standard was scraped off, re-extracted with chloroform and evaporated to dryness under nitrogen. The extract was taken up in $100 \mu \mathrm{L}$ acetonitrile in an amber-colored vial under refrigeration. AF was analyzed using a Jasco LC-2000 plus series HPLC system (Jasco, United States) with a fluorescence detector (RF-10Axl, Shimadzu) ( $\lambda$ exc $247 \mathrm{~nm} ; \lambda$ em $480 \mathrm{~nm}$ ) and a C18 column (Eclipse XDB-C18 $150 \times 4.6 \mathrm{~mm}, 5 \mu \mathrm{m}$; Agilent, United States, column temperature $35^{\circ} \mathrm{C}$ ) as described previously (Hanano et al., 2015). 


\section{Detection and Quantification of ROS in Fungal Tissue}

The accumulation of ROS was detected in fungal spores protoplast using a $2^{\prime}, 7^{\prime}$-dichlorofluorescin diacetate (DCFH-DA) staining protocol (Chang et al., 2011). The DCFH-DA, a cellpermeable non-fluorescent probe that turns to highly fluorescent $2^{\prime}, 7^{\prime}$-dichlorofluorescein in the presence of ROS (Sigma-Aldrich, United States) was dissolved into dimethyl sulfoxide (DMSO), and the stock solution was conserved at $-20^{\circ} \mathrm{C}$. Fungal protoplasts, previously washed with sterile deionized water, were incubated into $1 \mathrm{~mL}$ of freshly prepared solution of $10 \mu \mathrm{M}$ DCFH-DA in phosphate-buffered saline (PBS) for $4 \mathrm{~h}$ at $28^{\circ} \mathrm{C}$ in the dark. Later, the protoplasts were collected by a brief centrifugation and washed twice with PBS and subsequently examined under a Nikon Eclipse Ti-U fluorescent microscope. Micrographs were taken at a magnification of $10 \times$ using a Nikon Ti-U camera. The fluorescence intensity was analyzed using the software Image-Pro Plus 6.0.

\section{SOD and CAT Enzymatic Activities}

Preparation for enzyme activities was carried out as described previously (Zhang et al., 2012) with some modification. Briefly, $5 \mathrm{~g}$ of fungal tissues was homogenized with $5 \mathrm{~mL}$ potassium phosphate buffer ( $\mathrm{pH}$ 7.5) containing $1 \mathrm{mM}$ ethylenediaminetetraacetic acid (EDTA), 3 mM DL-dithiothreitol and $5 \%(\mathrm{w} / \mathrm{v})$ insoluble PVPP on ice. Subsequently, the homogenate was centrifuged at $12.000 \mathrm{rpm}$ for $5 \mathrm{~min}$, and the supernatant was therefore used for analyzing the enzymatic activities. Superoxide dismutase (SOD) activity was assayed by measuring its ability to inhibit the photochemical reduction of nitroblue tetrazolium (NBT) as described by Beauchamp and Fridovich (Beauchamp and Fridovich, 1971). Catalase (CAT) activity was measured by the method of Azevedo et al. (1998). Activity was determined by monitoring the decrease in absorbance due to $\mathrm{H}_{2} \mathrm{O}_{2}$ reduction at $240 \mathrm{~nm}$ for $2 \mathrm{~min}$.

\section{siRNA-Silencing of AfPXG Gene}

Small interference RNAs (siRNA) design primers, preparation of fungal protoplast and siRNA delivery were performed according to Hanano et al. (2018a). In brief, delivery of siRNA to protoplasts was done in sterile $1.5 \mathrm{~mL}$ tubes. A total of $10 \mu \mathrm{L}$ of siRNA primer (100 nM) was mixed with an equal volume of Lipofectin reagent (Invitrogen Life Technologies, United Kingdom) and kept for $15 \mathrm{~min}$ at $20^{\circ} \mathrm{C}$. A volume of $50 \mu \mathrm{L}$ of protoplasts was added, gently mixed and incubated at $20^{\circ} \mathrm{C}$ for $24 \mathrm{~h}$ to allow transfection to proceed. The transfected protoplasts were therefore inoculated in $10 \mathrm{~mL}$ of PD medium with $1.2 \mathrm{M}$ of sorbitol for 7 days at $28^{\circ} \mathrm{C}$ in the dark. All experiments were performed using three biological replicates.

\section{Inoculation of Maize Seeds With A. flavus and Biomass Estimation}

A quantity of $100 \mathrm{~g}$ of maize (Zea mays) was sterilized by immersion into $70 \%$ ethanol for $1 \mathrm{~min}$. After drying, grains were placed in a sterile petri plate and directly inoculated with $200 \mu \mathrm{l}$ of liquid culture of A. flavus in PD broth. Inoculated grains were incubated at $28^{\circ} \mathrm{C}$ for 7 days. Fungal biomass was estimated on day 7 by careful washing of infected grains, filtration and then weighing the fungal growth expressed in grams of fresh weight per $100 \mathrm{~g}$ of grains.

\section{Statistical Analysis}

All data presented are expressed as means \pm standard deviation (SD). Comparisons between control and treatments were evaluated by $t$-test. Difference from control was considered significant as $P<0.05$, very significant as $P<0.01$, and highly significant as $P<0.001$.

\section{RESULTS}

\section{Characterization of the TCDD-Exposed Phenotype of $A$. flavus}

The photographs presented in Figure 1A show that the TCDDexposed A. flavus were phenotyped by limitation in fungal growth and activation of conidia formation compared to control. Inversely to control, the mycelium dry weight of fungi per plate was significantly reduced when they were exposed to TCDD and formed only about half of control growth at the highest dose of TCDD (50 $\mathrm{ng} \mathrm{L}^{-1}$ ) on days 3, 5, and 7 after inoculation (Figure 1B). More surprisingly, the TCDD-exposed fungi tended to produce spores more actively compared to the control. For example, on day 7, while the fungus that was exposed to $50 \mathrm{ng}$ $\mathrm{L}^{-1}$ produced more than $14 \times 10^{6} \mathrm{~mL}^{-1}$, the control produced about $9.6 \times 10^{6} \mathrm{~mL}^{-1}$ (Figure 1C). Furthermore, the blue fluorescent spot of $\mathrm{AFB}_{1}$ was increasingly detected on the TLC as a function of TCDD treatment (Figure 1D). Quantitatively speaking, the amount of $\mathrm{AFB}_{1}$, measured by HPLC, was doubled in the TCDD-exposed fungi compared to control, where the highest concentration of $\mathrm{AFB}_{1}\left(24.8 \mu \mathrm{g} \mathrm{mL}^{-1}\right)$ was detected when $A$. flavus was exposed to $50 \mathrm{ng} \mathrm{\textrm {L } ^ { - 1 }}$ on day 7 after inoculation (Figure 1E). Together, these data suggest that dioxin exposure causes certain limitation in fungal growth and boosts conidiation and $\mathrm{AFB}_{1}$ production in A. flavus.

\section{The TCDD-Exposed Phenotype of A. flavus Has an Enhanced Level of Oxidative Status}

It is well know that AF biosynthesis is naturally stimulated under stress oxidative status caused by a high level of ROS (Reverberi et al., 2008). Thus, the high production of AF by the TCDDexposed $A$. flavus raises the question on whether such exposure will boost the accumulation of ROS in fungal tissues. To evaluate that, the accumulation of ROS in fungal spore protoplasts was detected using the DCFH-DA, a cell-permeable non-fluorescent probe that turns to highly fluorescent $2^{\prime}, 7^{\prime}$-dichlorofluorescein in the presence of cellular ROS. As the photographs show, the intensity of green fluorescence that was proportionally related to the amount of ROS was remarkably augmented in a response to the exposure to TCDD at 10 and $50 \mathrm{ng} \mathrm{mL}-1$ in fungal spore protoplasts compared to their respective controls (Figure 2A). When the fluorescence intensity was analyzed by the software 
A
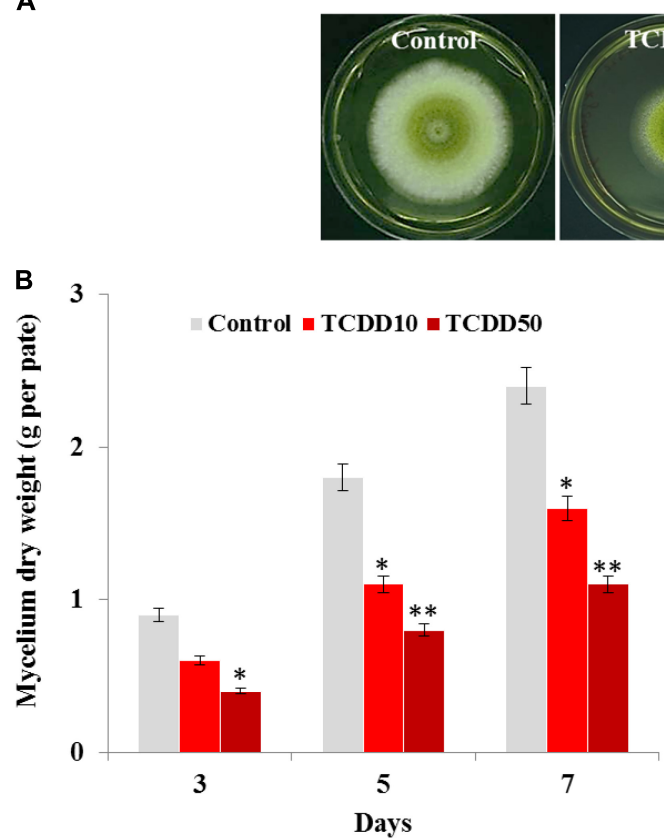

C

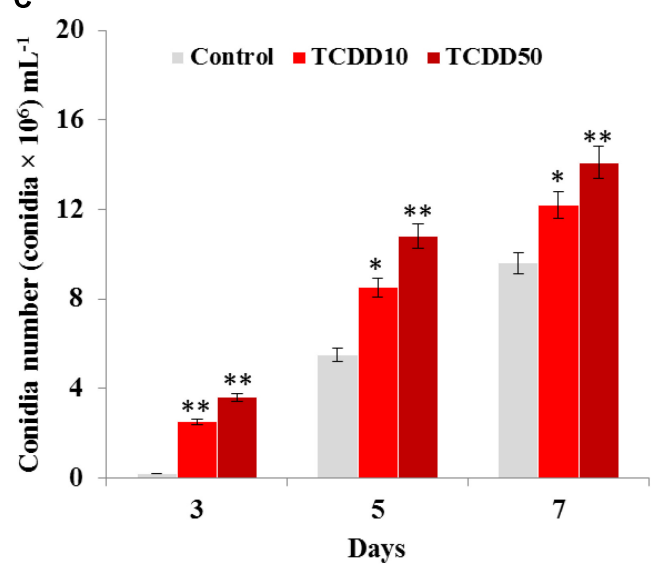

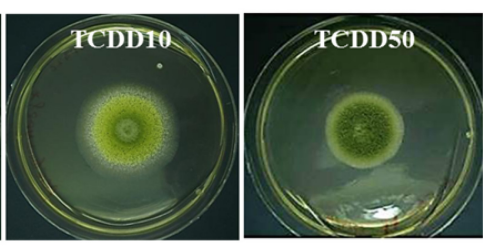

D

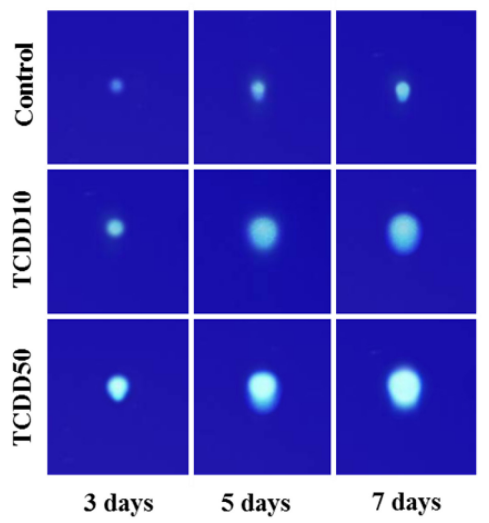

$E$

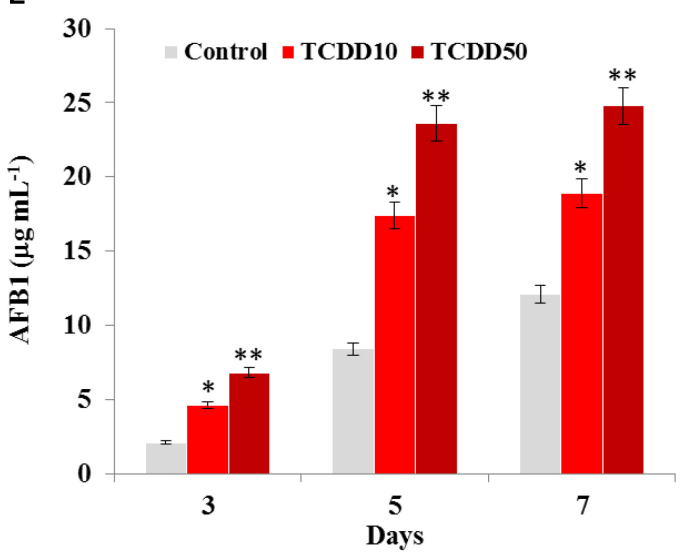

FIGURE 1 | Characteristic of $A$. flavus TCDD-exposed phenotype. (A) Photographs of 5-day-old cultures of $A$. flavus on PDA-plates upon the exposure to TCDD at 10 and $50 \mathrm{ng} \mathrm{L}^{-1}$ that referred as to TCDD10 and TCDD50, respectively, compared with non-exposed fungus control. (B,C) Variation in fungal mycelium dry weight and spore number, respectively, as a function of the exposure to TCDD at both doses. (D) Sections of Thin Layer Chromatography (TLC) plate showing the blue-fluorescent spots under the UV light that correspond to the $\mathrm{AFB}_{1}$ secreted by the TCDD-exposed fungi compared to control. (E) Quantitative data of AFB 1 as estimated by UV-detector HPLC. All measurements were done in triplicate and the presented data are means $\pm S D(n=3)$. Difference between treatments and control was significant $\left({ }^{*} P<0.05\right)$ or very significant $(* * P<0.01)$ when analyzed by $t$-test.

Image-Pro Plus 6.0, we stated that such intensity was higher about 3.1- to 3.8-fold in protoplasts exposed to TCDD at 10

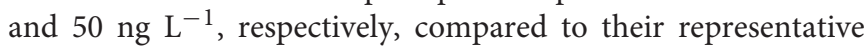
controls (Figure 2B). In connection with ROS level, we have measured the cellular enzymatic activities of SOD and CAT; both enzymes are activated by the excess ROS and react to neutralize the $\mathrm{O}^{2-}$ and $\mathrm{H}_{2} \mathrm{O}_{2}$, respectively. SOD activity was stimulated by a factor of 2 and 3 in TCDD-exposed fungi to 10 and $50 \mathrm{ng}$ $\mathrm{mL}^{-1}$, respectively, compared to controls (Figure 2C). Also, CAT activity was induced 2.7- to 3.6-fold in such treatments compared to controls (Figure 2C). These data suggest that the exposure to dioxin led to enhanced ROS accumulation in fungal tissue, and subsequently the ROS-scavenging enzymatic activities were induced.

TCDD Induces the Expression of AfPXG, the Accumulation of LDs and Subsequently the Production of $\mathrm{AFB}_{1}$ in

\section{A. flavus}

We recently reported that the caleosin/peroxygenase AfPXG of A. flavus modulates the biosynthesis of $\mathrm{AF}$ and its trafficking via the LDs (Hanano et al., 2018a). Likewise, certain isoforms of plant caleosins/peroxygenase were strongly induced by 

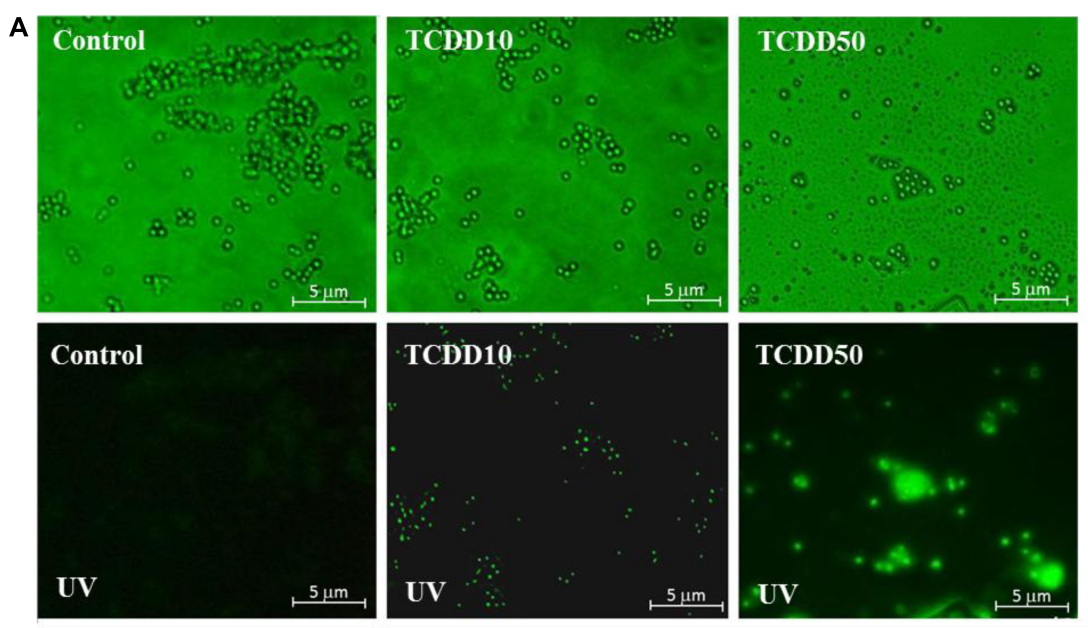

B
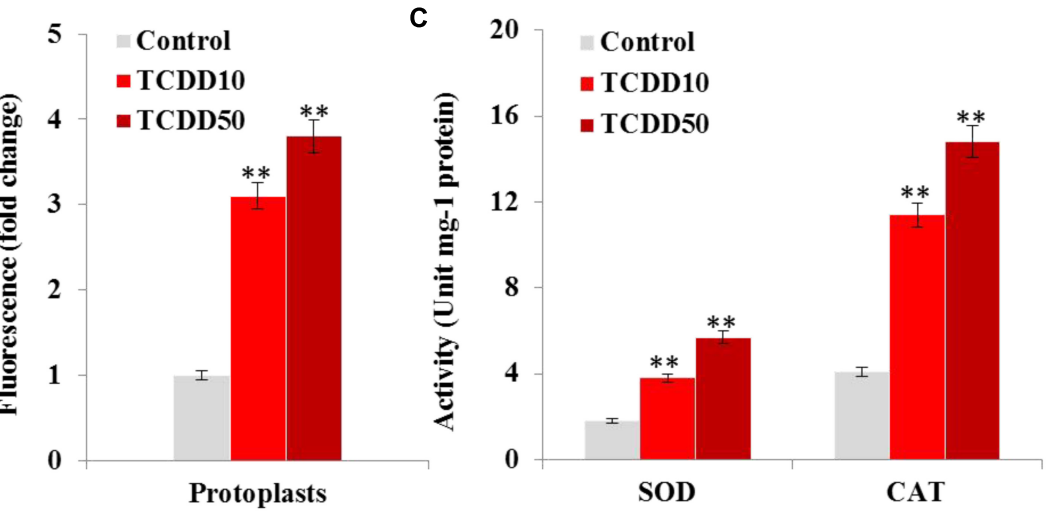

FIGURE 2 | The exposure to TCDD enhances the accumulation of ROS in fungal tissues. (A) Micrographs of fungal spore protoplasts stained with DCFH-DA, a cell-permeable non-fluorescent probe that turns to highly fluorescent $2^{\prime}, 7^{\prime}$-dichlorofluorescein in the presence of cellular ROS. Samples were examined under a Nikon Eclipse Ti-U fluorescent microscope and micrographs recorded at a magnification of $10 \times$ a using a Nikon Ti-U camera. Bar represents $5 \mu \mathrm{m}$. (B) The ROS fluorescence intensity was analyzed by software Image-Pro Plus 6.0. The fold change in fluorescence intensity was estimated by comparing the TCDD-treated samples for spore protoplasts with their respective controls that were considered as 1 . Data were shown as the mean \pm SD. (C) Enzymatic activities of SOD and CAT in fungal tissues in response to TCDD exposure at indicated concentrations. All measurements were done in triplicate and the presented data are means $\pm S D$ $(n=3)$. Difference between treatments and control was significant $(* P<0.05)$ or very significant $(* * P<0.01)$ when analyzed by $t$-test.

dioxin (Hanano et al., 2018b). In connection with this, we were interested in gaining more insight into the biological implication of AfPXG in fungal responses to dioxin exposure. At transcription level, the expression of AfPXG was significantly induced upon exposure to TCDD. The transcript level of AfPXG was augmented 6.5- and 9.2-fold as a function of

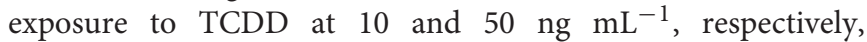
compared with control (Figure 3A). This was synchronized with a similar increase in protein level of AfPXG as well as in its enzymatic activity, measured by hydroxylation of aniline, where this activity was increased from 0.3 in the control to 1.8 and 2.3 ( $\mu \mathrm{mol} \mathrm{min} \mathrm{mg}^{-1}$ ) in the exposed fungi to 10 and $50 \mathrm{ng} \mathrm{mL}$ of TCDD (Figure 3B). Subsequently, the TCDD-exposed fungi accumulated an increasing number of LDs as shown in the micrographs under light microscope (Figure 3C). Unlike the LDs isolated from control fungi, the number of LDs isolated from TCDD-exposed fungi was augmented by a factor of 5 , and this number was stable $24 \mathrm{~h}$ after preparation compared with the critical stability of control LDs (Figure 3D). The increasing accumulation of LDs in the TCDDexposed fungal tissues raises the question about their cellular activity in the trafficking and secretion of AF. Interestingly, despite the decreasing amount of $\mathrm{AFB}_{1}$ that detected in the TCDD-exposed fungal tissues (Figure 3E), these fungi secreted more $\mathrm{AFB}_{1}$ into the medium (Figure 3F) and this elevated their secretion ratio to about 0.9 versus 0.7 for the control (Figure 3G). The high production of $\mathrm{AFB}_{1}$ upon exposure to TCDD was effectively related with important increases in the transcripts level of certain key genes, e.g., alfD, alfG, alfI, alfL, alfM, alfN, alfQ, alfR, and alfS of the AF biosynthesis pathway (Figure $3 \mathbf{H}$ ). These data suggest that the exposure of $A$. flavus to dioxin induces the expression of AfPXG, increases the accumulation of stable LDs and therefore enhances the production of AF. 
A

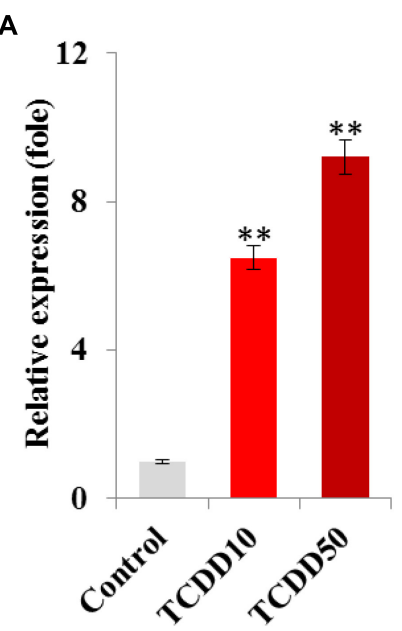

E

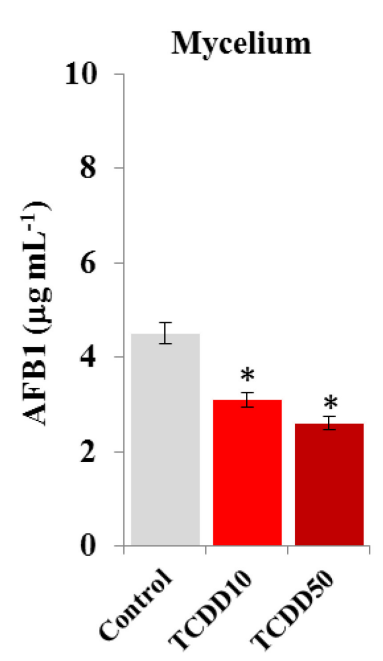

H
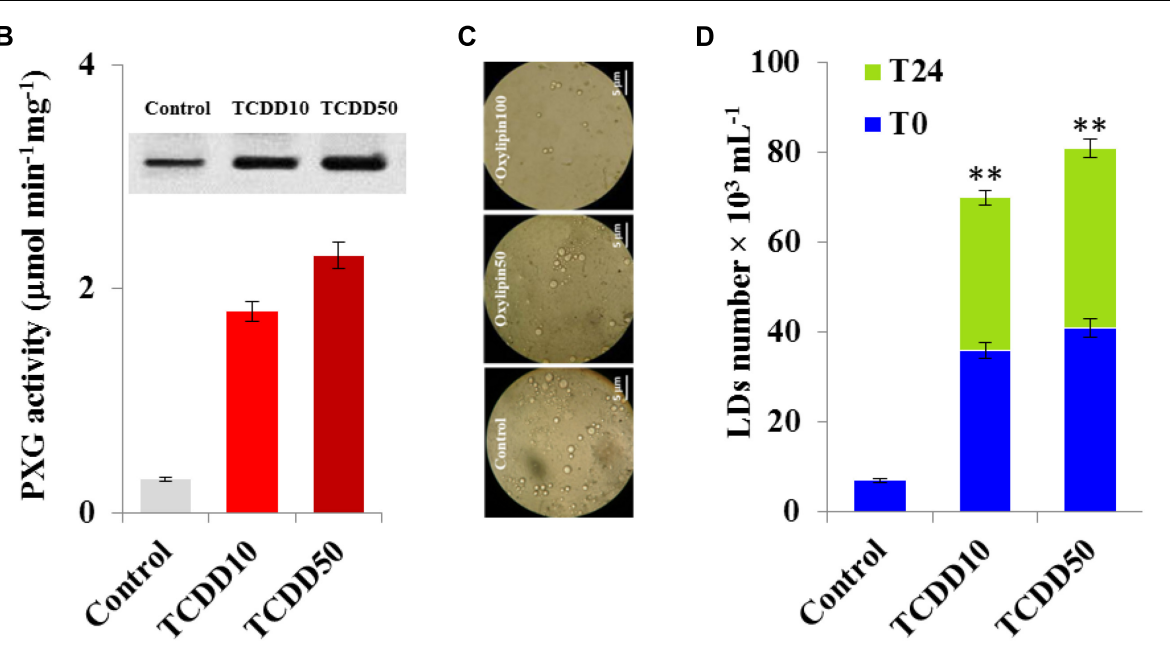

F

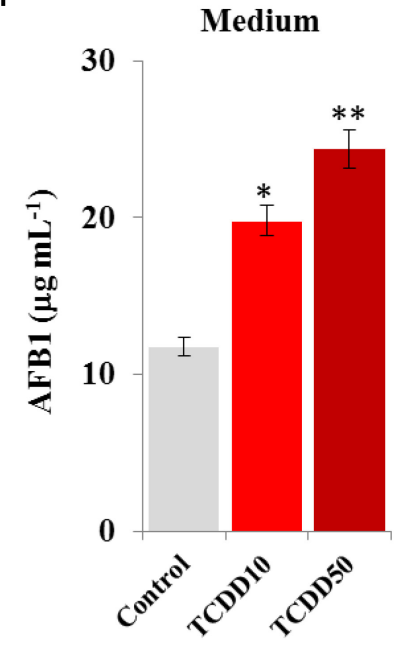

G

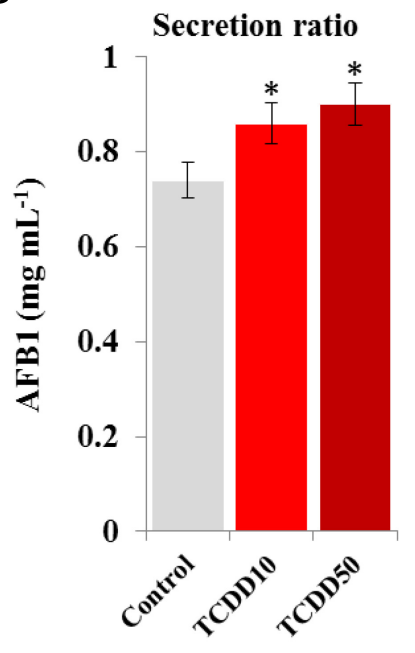

Fold-change in genes expression

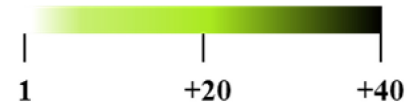

aflA aflB aflC alfD afle affG aflH afl aflJ aflK aflL aflM aflN aflo affP aflQ aflR afts

\section{Control \\ TCDD10 \\ TCCD50}

FIGURE 3 | The TCDD induces the functional expression of AfPXG, the accumulation of LDs and the production of AfB1. (A) Transcripts level of AfPXG gene, evaluated by RT-qPCR, in the fungal tissues exposed or non-exposed to TCDD. (B) The peroxygenase activity of AfPXG, estimated by the hydroxylation of aniline at $310 \mathrm{~nm}$. (C) Micrographs of LDs isolated from fungal tissues exposed or not exposed to TCDD. Samples were examined under a LEICA MPS60 light microscope and the images were taken at a magnification of $40 \times$ immediately after preparation. Bar represents $5 \mu \mathrm{m}$. (D) LD number was estimated using a hemocytometer. (E,F) Measurement of AFB1 in the fungal mycelium and in the culture medium of $A$. flavus exposed or not exposed to TCDD. (G) Secretion ratio of AFB1 by fungi exposed or not exposed to TCDD (calculated as the ratio of AFB1 in the medium to AFB1 in medium plus mycelia in a $100 \mathrm{~mL}$ culture). (H) Relative quantification $\mathrm{RQ}=2^{(-\Delta \Delta C T)}$ of AF-biosynthesis gene transcripts upon the exposure to TCDD compared to control. The color scale (white-green-black) indicates relative changes of transcripts of $1,+20$, and +40 -fold, respectively. For each gene, the expression level in the control was defined as 1 , and the corresponding increase in gene transcript under treatments was calculated. All measurements were done in triplicate and the presented data are means $\pm S D(n=3)$. The differences between control and treatments were significant when analyzed by $t$-test $\left({ }^{*} P<0.05\right.$; $\left.{ }^{* *} P<0.01\right)$. 


\section{TCDD-Induced Hyperaflatoxicogenicity Is Reduced in AfPXG-Silencing Strain}

To confirm the biological link between the TCDD-induced aflatoxicogenicity and the function of AfPXG, the TCDD was administrated to A. flavus WT as well as to AfPXG-silenced strain (referred as to siAfPXG) in which the AfPXG gene was silenced by about half using siRNAs (Hanano et al., 2015, 2018a). Our data indicated that the silencing of AfPXG was briefly restored upon treatment with TCDD, but its transcript level was still about 42- to 46-fold lower compared to the control (Figure 4A). In parallel, the silencing of AfPXG was also confirmed by the absence of peroxygenase activity in the control as well as in the TCDD-treated samples (Figure 4B). Furthermore, the treatment with TCDD, at both concentrations, did not lead to increased accumulation of LDs in the siAfPXG strain as it did in the WT (Figure 4C). Subsequently, the treatments with TCDD at both concentrations did not provoke an over-secretion of $\mathrm{AFB}_{1}$ in the siAfPXG strain as it did in the WT. For example, while the production of $\mathrm{AFB}_{1}$ in the WT treated with the highest dose of TCDD was highly stimulated to reach about $23.5 \mu \mathrm{g}$ $\mathrm{mL}^{-1}$, this treatment failed to provoke a similar effect in the siAfPXG strain where its $\mathrm{AFB}_{1}$ production did not exceed $1.8 \mu \mathrm{g}$ $\mathrm{mL}^{-1}$ (Figure 4D). Apparently, the failure of the TCDD-exposed siAfPXG strain in stimulating the AF production was related with a severe down-regulation of a set of key genes in AFbiosynthesis pathway. The heat map (Figure 4E) shows that upon its exposure to TCDD, the siAfPXG strain still had low levels of alfB, alfC, alfD, alfG, alfI, alfL, alfM, alf $N$, alfQ, alfR, and alfS transcripts compared with WT. Altogether, these results suggest that the TCDD-induced aflatoxicogenicity of A. flavus is likely mediated by AfPXG.

\section{The TCDD-Exposed A. flavus Shows More Aggressivity to Infect Maize Grains}

The induced aggressivity of $A$. flavus caused by the exposure to TCDD was assayed in vitro using grains of maize. For that, the spores of A. flavus WT strain grown in contaminated medium with TCDD were collected and used to infect the grains. Then, the fungal biomass and AF production were evaluated and compared with control. The photographs of infected grains (Figure 5A) show a brief limitation in fungal growth but a more pronounced activity in conidiation of TCDD-exposed fungi compared to the non-exposed fungus. This was confirmed by the decreasing amount of fungal biomass, expressed as ( $\mathrm{g}$ dry weight per $10 \mathrm{~g}$ of grains) in the TCDD-exposed fungi, at both concentrations (2.3 and 3.5-fold) compared to control (Figure 5B). Inversely, the AF production was doubled and tripled in the infected grains with the exposed fungi to TCDD at 10 and $50 \mathrm{ng} \mathrm{mL}^{-1}$ compared to control (Figure 5B). These data indicate that the exposure of A. flavus to dioxin could likely boost its aflatoxicogenicity.

\section{DISCUSSION}

Aflatoxins are globally considered the most perilous food contaminants with proven toxicological, economic and social impacts. The fact that these toxins are mainly produced by certain fungal species that are known by their remarkable adaptive capabilities with various environmental niches, makes their management an effective challenge (Weckbach and Marth, 1977; Mehl et al., 2012). In this context, the focus on the biological impacts of environmental factors on the fungal growth, and development in general and its aflatoxicogenicity in particular, is a decisive rule for globally governing the contamination with aflatoxins in a sustainable minded manner. In line with this, many ecological studies have demonstrated the biological feedback of environments on the aggressivity/aflatoxicogenicity of AF-producing fungi (Gilbert et al., 2017; Medina et al., 2017). Unexpectedly, despite the ultimate connection of AF-producing fungi with soil, the biological impacts of soil contaminants, more particularly the POPs, are still obscure.

In light of this, the current study shows that the in vitro exposure of A. flavus to dioxin results in a phenotype typified by a peculiarly reducing in fungal vegetative growth and a noteworthy tendency to conidiation. First, in the absence of comparative data in fungi, the limitation in fungal mycelial growth caused by TCDD could be supported by a similar phenomenon in the experimental animals exposed to TCDD. A characteristic feature of acute exposure to dioxin is a dramatic decline in body weight, a phenomenon known as the wasting syndrome (Tuomisto et al., 1995; Tsujimoto et al., 2013; Hutin et al., 2018). With surprising similarity, a significant reduction in the fresh weight of leaves and seeds was also reported for plants that were experimentally exposed to TCDD (Zhang et al., 2012; Hanano et al., 2014a, 2018b). Beyond the wasting of weight, the dioxinexposed organisms tended to implant a specific profile of cellular fatty acids, which leads to a puzzling and dramatic perturbation of the regulatory systems for energy balance (Hanano et al., 2018b,c). Moreover, the TCDD-induced phenotype of A. flavus was characterized by a remarkable ability to sporulate. Indeed, there are multiple lines of genetic, molecular and biochemical evidence that confirm the presence of a biological link between the fungal sporulation and the accumulation of secondary metabolites (SM) and more particularly the AF, where their production was also enhanced upon exposure to TCDD. In this context, earlier reports have shown that the environmental conditions required for sporulation and the accumulation of SM were often similar and were more strict than those for vegetative growth (Sekiguchi and Gaucher, 1977; Guzman-De-Pena and Ruiz-Herrera, 1997). This included, but was not limited to, temperature (Espeso et al., 1993), air-surface interface (GuzmanDe-Pena and Ruiz-Herrera, 1997), medium pH (Buchanan and Ayres, 1975), nature of nutrients (Keller et al., 1997) and certain compounds present in seeds commonly infected by Aspergillus species (Goodrich-Tanrikulu et al., 1995; Burow et al., 1997; Calvo et al., 1999; Zeringue, 2000). In a more evolved manner, it was suggested that certain SMs act as sporogenic factors. For example, several lines of genetic evidence have shown that the accumulation of natural pigments in fungal tissues, such as melanin, is associated with fungal sporulation (Kawamura et al., 1999). Of particular interest, the relationship between fungal sporulation and mycotoxin biosynthesis has been corroborated for AF biosynthesis in A. flavus and A. parasiticus as well as for 

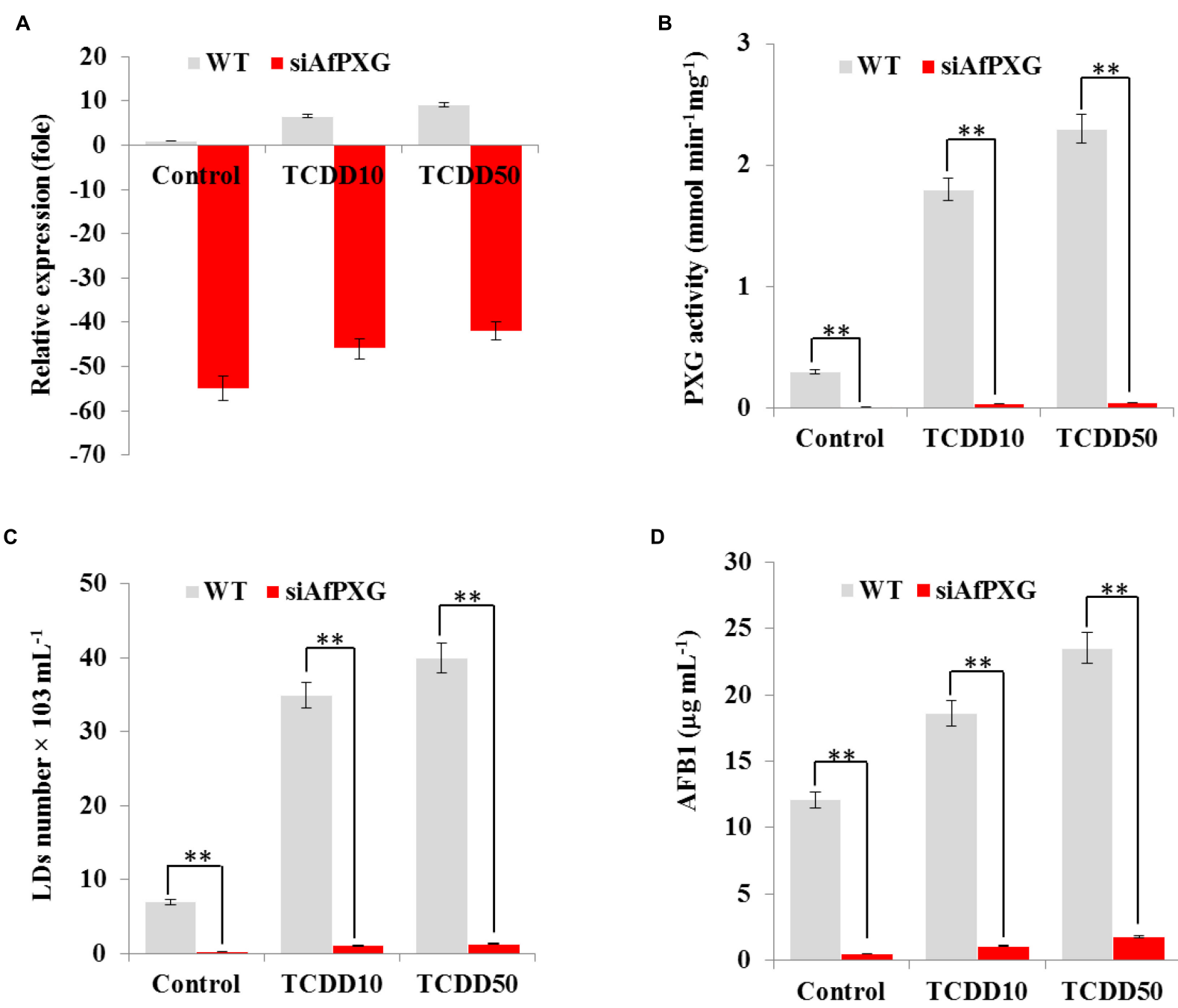

E

Fold-change in genes expression

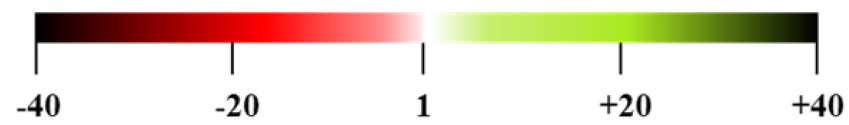

afle aflB aflC alfD afle aflG aflH afl aflJ aflK aflL aflM aflN aflo aflP aflQ aflR afls

WT0

siAfPXG0

WT10

siAfPXG10

WT50

siAfPXG50 
FIGURE 4 | The TCDD-induced hyperaflatoxicogenic phenotype is abolished in the AfPXG-silencing strain. (A) Relative quantification of AfPXG transcripts in the AfPXG-silencing strain (siAfPXG) and the wild type (WT) upon their exposure to TCDD at the indicated concentrations. (B) Estimation of the peroxygenase activity in siAfPXG and WT after exposure to TCDD compared with their respective controls. The activity was estimated by the hydroxylation of aniline at 310 nm. (C) Number of LDs isolated from siAfPXG and WT after exposure to TCDD. (D) Concentration of AFB1 secreted by siAfPXG and WT upon their exposure to TCDD at both concentrations compared with their respective controls. (E) Transcripts levels of the AF-biosynthesis genes in fungal tissue of siAfPXG and WT after their exposure to TCDD at both concentrations. This was carried out using the RT-qPCR system. Three measurements were done in three cDNAs prepared from three individual fungal tissues for each line. The color scale (red-white-green) indicates positive changes of transcript abundance of - 40-, 1, and +40-fold, respectively. For each gene, the expression level in the control was defined as 1, and the corresponding abundance changes under treatments were calculated directly using the software installed in the Applied Biosystems qPCR system. The differences between treatments and control were significant when analyzed by $t$-test $\left({ }^{*} P<0.05 ;{ }^{*} P<0.01\right)$.
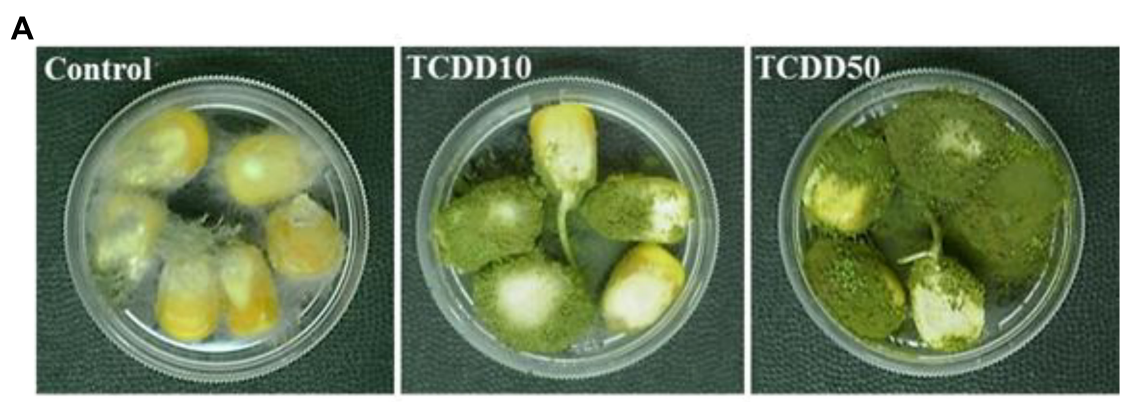

B

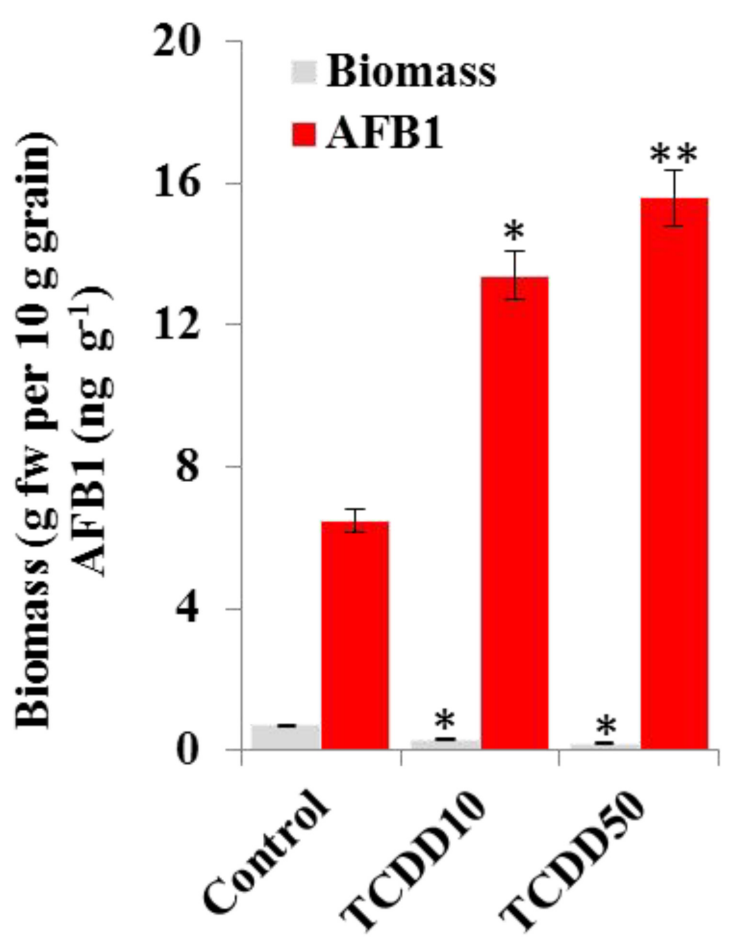

FIGURE 5 | The exposure to TCDD boosts the aggressivity of $A$. flavus against the maize grains. (A) Photographs of infected maize grains with A. flavus previously exposed to TCDD at 10 and $50 \mathrm{ng} \mathrm{L}^{-1}$ referred to as TCDD10 and TCDD50, respectively, compared with non-exposed fungus control. After sterilizing, grains were placed in a sterile petri plate and directly inoculated with $200 \mu$ l of liquid culture of $A$. flavus in PD broth contaminated or not contaminated with TCDD. The photographs were taken 8 days after inoculation. (B) Estimation of fungal biomass and AFB1 production in the three samples. Asterisks indicate significant differences between treatments and control $\left({ }^{*} P<0.05\right.$; $\left.{ }^{*} P<0.01\right)$.

sterigmatocystin (ST) biosynthesis in Aspergillus nidulans. The non-producing AF/ST mutants that had a deletion in aflR, a gene encoding a regulatory protein that modulates the expression of AF/ST-biosynthesis cluster genes, failed in the formation of spores in all three Aspergillus sp. (Trail et al., 1995). Inversely, the overexpression of aflR enhances the production of $\mathrm{AF}$ and the formation of spores ( $\mathrm{Yu}$ et al., 1996), and this is in line with our data showing an increasing level in aflR transcripts in 
fungal tissues after exposure to dioxin. Furthermore, the fluffy mutants of A. nidulans and A. flavus that have a defective G-protein signaling pathway resulted in an aconidial, aflatoxinnull phenotype (Calvo et al., 2002; Affeldt et al., 2012). More recently, the nucleoside diphosphate kinase (AfNDK), which was newly characterized in A. flavus, regulates spore and sclerotia development and is involved in plant infection (Wang et al., 2019). Additionally, the HosA, a new histone deacetylase recently identified in A. flavus, plays a determinant role in growth, development and AF biosynthesis (Lan et al., 2019).

Substantial dioxin-induced overproduction of AF can be an expected result of the increasing level of ROS in the fungal tissues upon their exposure to TCDD. In line with this, dioxins have a proven effect in inducing the accumulation of ROS in exposed animals (Bentli et al., 2016; Liu et al., 2016) and plants (Hanano et al., 2014a), suggesting a similar effect in fungi. Otherwise, the enhanced level of ROS was effectively accompanied with a significant stimulation of SOD and CAT activities, the two main scavengers of $\mathrm{O}_{2^{\bullet-}}$ and $\mathrm{H}_{2} \mathrm{O}_{2}$, respectively. This could be viewed as a part of the complex anti-oxidative defense system used by the organism to minimize the oxidative damage initiated by the ROS access. The activities of both enzymes were stimulated in plant tissues upon exposure to dioxin, polyaromatic hydrocarbons and some pesticides (Liu et al., 2009; Zhang et al., 2012; Hanano et al., 2014a).

In respect to the induction of AfPXG by TCDD, the expression of this caleosin is modulated by various biotic and abiotic stresses in several fungal species e.g., Aspergillus oryzae (Machida et al., 2005; Akao et al., 2007), Ustilago maydis (Tollot et al., 2016), and Erysiphe necator (Wakefield et al., 2011). Furthermore, the TCDD-induced expression of AfPXG led to an increase in the accumulation and the stability of LDs in fungal tissues. This result can be supported by recent findings showing that the heterologous expression of AfPXG in yeast led to a massive accumulation of stable LDs (Hanano et al., 2015). Likewise, the AfPXG-overexpressed line of A. flavus accumulated more LDs than the wild type (Hanano et al., 2018a), and this was synchronized with an elevated level in AF secretion. It is likely that the expression of AfPXG could be coordinated by TCDD at two levels;

(i) At the level of AfPXG enzymatic activity, it is now well recognized that AfPXG experimentally catalyzes the reduction of fatty acid hydroperoxides (FA-OOH) into their corresponding alcohols $(\mathrm{AF}-\mathrm{OH})$ as the plant caleosins/peroxygenases typically do (Hanano et al., 2006, 2016b). The biological impacts of this activity, characterized as the newest branch of the oxylipins biosynthesis pathway, have been interestingly underlined in plants (Blee et al., 2014; Charuchinda et al., 2015) but less in fungi (Fan et al., 2015). For example, it was documented that the endogenous treatment of Aspergillus with plant-originated FA-OOH represses AF biosynthesis and lengthens the time during which the AF gene transcripts accumulate (Burow et al., 1997). More recently, the knockout of AfPXG in A. flavus resulted in a considerable accumulation of FA$\mathrm{OOH}$ in fungal tissues that have been accompanied with developmental anomalies and lowering in AF production (Hanano et al., 2018a).

(ii) At the level of AfPXG's structural role in LDs assembly, the caleosins encoding genes are present in the vast majority of publicly available fungal genomic sequences including all Aspergillus spp., and they contain at least one copy of a highly conserved transmembrane domain enabling the caleosin proteins to be targeted in the monolayer membrane of LDs (Murphy, 2012; Hanano et al., 2015; Rahman et al., 2018a,b). The structural role of fungal caleosins in impacting the assembly and the stability of LDs is well demonstrated (Froissard et al., 2009; Jamme et al., 2013; Hanano et al., 2015), and this is in line with our results indicating that the TCDD-exposed fungi expressed more AfPXG and therefore accumulated more of LDs than the control. Otherwise, similar inductions of certain isoforms of caleosins were also reported in plants that have been experimentally exposed to TCDD (Hanano et al., 2016b, 2018b,c).

In connection with the TCDD-induced hyperaflatoxicogenicity, the implication of LDs in trafficking and exporting of AF has been recently reported (Hanano et al., 2018a), where the increasing number of LDs in the AfPXGoverexpressed line of A. flavus showed an increasing capability to sequestrate the $\mathrm{AF}$ and this was positively correlated with a high secretion ration of AF into the medium. In line with this, the role of LDs as transient repositories of lipophilic and hydrophilic compounds, from small molecules such as DNA, signal molecules, SM to large proteins, is well established (Chang et al., 2015; Gao and Goodman, 2015; Kory et al., 2016; Schuldiner and Bohnert, 2017). Taken together, our data suggest that the dioxin-induced hyperaflatoxicogenic phenotype of A. flavus is likely mediated by the caleosin/peroxygenase AfPXG. This could be particularly supported by using the AfPXG-silencing strain of A. flavus, where the typical TCDD-induced phenotype observed in the WT was completely abolished in the AfPXG-silencing strain. Finally, we found that the TCDD-exposed A. flavus had increased virulence against the grains of maize in terms of fungal invasion, sporulation and AF production. These observations suggest that contamination of soil with dioxin can influence the invasion capacity of soil-dwelling A. flavus, more particularly the fungal spores, empowering its aflatoxicogenicity. Similar worrying scenarios were suggested in response to possible adverse consequences of climate change (Medina et al., 2014; Assuncao et al., 2018).

\section{CONCLUSION}

Our study sheds light, for the first time, on the possible biological feedback of persistent environmental pollutants, notably the dioxins on the aggressivity of AF-producing fungi in terms of their ability to infect and contaminate the crops. The production of aflatoxins and their subsequent prevalence in agricultural commodities are affected by environmental changes including persistent pollutants such as dioxins, which are increasingly 
recognized as direct contaminants resulting from the forests burning. Our data showed that the in vitro exposure of $A$. flavus to dioxin considerably increased its virulence in term of sporulation and aflatoxicogenicity. We suggest that this hyper-aflatoxicogenic phenotype is mediated by the caleosin/peroxygenase AfPXG that has proven functions in controlling the biosynthesis and trafficking of aflatoxins in A. flavus. This study highlights one unpredicted consequence of climate change that is relevant to the food safety. Our observations suggest that global food safety could be impacted by climate change, and this will possibly present new challenges in the near future to combat climate change in a global manner as well as to preserve, and even more to reinforce, the global regulations of food safety.

\section{DATA AVAILABILITY STATEMENT}

All datasets generated for this study are included in the manuscript/supplementary files.

\section{REFERENCES}

Affeldt, K. J., Brodhagen, M., and Keller, N. P. (2012). Aspergillus oxylipin signaling and quorum sensing pathways depend on g protein-coupled receptors. Toxins 4, 695-717. doi: 10.3390/toxins4090695

Akao, T., Sano, M., Yamada, O., Akeno, T., Fujii, K., Goto, K., et al. (2007). Analysis of expressed sequence tags from the fungus Aspergillus oryzae cultured under different conditions. DNA Res. 14, 47-57. doi: 10.1093/dnares/dsm008

Anasonye, F., Winquist, E., Kluczek-Turpeinen, B., Räsänen, M., Salonen, K., Steffen, K. T., et al. (2014). Fungal enzyme production and biodegradation of polychlorinated dibenzo-p-dioxins and dibenzofurans in contaminated sawmill soil. Chemosphere 110, 85-90. doi: 10.1016/j.chemosphere.2014.03.079

Assuncao, R., Martins, C., Viegas, S., Viegas, C., Jakobsen, L. S., Pires, S., et al. (2018). Climate change and the health impact of aflatoxins exposure in Portugal - an overview. Food Addit. Contam. Part A Chem. Anal. Control Expo. Risk Assess. 35, 1610-1621. doi: 10.1080/19440049.2018.1447691

Azevedo, R. A., Alas, R. M., Smith, R. J., and Lea, P. J. (1998). Response of antioxidant enzymes to transfer from elevated carbon dioxide to air and ozone fumigation, in the leaves and roots of wild-type and a catalase-deficient mutant of barley. Physiol. Plant. 104, 280-292. doi: 10.1034/j.1399-3054.1998.1040 217.x

Beauchamp, C., and Fridovich, I. (1971). Superoxide dismutase: improved assays and an assay applicable to acrylamide gels. Anal. Biochem. 44, 276-287. doi: 10.1016/0003-2697(71)90370-8

Bentli, R., Ciftci, O., Cetin, A., and Otlu, A. (2016). Anti-inflammatory Montelukast prevents toxic effects of 2,3,7,8-tetrachlorodibenzo-p-dioxin: oxidative stress, histological alterations in liver, and serum cytokine levels. Toxicol. Ind. Health 32, 769-776. doi: 10.1177/0748233713505894

Bertuzzi, T., Rastelli, S., Mulazzi, A., and Pietri, A. (2011). Evaluation and improvement of extraction methods for the analysis of Aflatoxins B1, B2, G1 and G2 from naturally contaminated maize. Food Anal. Methods 5, 191-199. doi: 10.1016/j.chroma.2013.10.006

Blee, E., Boachon, B., Burcklen, M., Le Guedard, M., Hanano, A., Heintz, D., et al. (2014). The reductase activity of the Arabidopsis caleosin RESPONSIVE TO DESSICATION20 mediates gibberellin-dependent flowering time, abscisic acid sensitivity, and tolerance to oxidative stress. Plant Physiol. 166, 109-124. doi: $10.1104 /$ pp.114.245316

Blee, E., and Durst, F. (1987). Hydroperoxide-dependent sulfoxidation catalyzed by soybean microsomes. Arch. Biochem. Biophys. 254, 43-52. doi: 10.1016/00039861(87)90079-8

Boucher, J., Cengelli, F., Trumbic, D., and Marison, I. W. (2008). Sorption of hydrophobic organic compounds (HOC) in rapeseed oil bodies. Chemosphere 70, 1452-1458. doi: 10.1016/j.chemosphere.2007.08.065

\section{AUTHOR CONTRIBUTIONS}

$\mathrm{AH}$ led the work, designed all experiments in biochemistry and molecular biology, and wrote the manuscript. MS and IA carried out all experimental work. All authors read and approved the final manuscript.

\section{ACKNOWLEDGMENTS}

We would like to thank Prof. Dr. Ibrahim Othman, Director General of the AECS, and Dr. Nizar Mirali, Head of the Department of Molecular Biology and Biotechnology, for their crucial support. We also thank Prof. Marie-Laure Fauconnier, from the faculty of Agricultural Sciences, Gembloux, Belgium, who kindly gifted us the strain NRRL3357. We also kindly thank Prof. Denis J. Murphy, University of South Wales, United Kingdom, for his precious help in critically reading the manuscript.

Buchanan, R. L. Jr., and Ayres, J. C. (1975). Effect of initial pH on aflatoxin production. Appl. Microbiol. 30, 1050-1051.

Burow, G. B., Nesbitt, T. C., Dunlap, J., and Keller, N. P. (1997). Seed Lipoxygenase products modulate Aspergillus mycotoxin biosynthesis. Mol. Plant Microbe Interact. 10, 380-387. doi: 10.1094/mpmi.1997.10.3.380

Calvo, A. M., Hinze, L. L., Gardner, H. W., and Keller, N. P. (1999). Sporogenic effect of polyunsaturated fatty acids on development of Aspergillus spp. Appl. Environ. Microbiol. 65, 3668-3673.

Calvo, A. M., Wilson, R. A., Bok, J. W., and Keller, N. P. (2002). Relationship between secondary metabolism and fungal development. Microbiol. Mol. Biol. Rev. 66, 447-459. doi: 10.1128/mmbr.66.3.447-459.2002

Chang, P. K., Scharfenstein, L. L., Luo, M., Mahoney, N., Molyneux, R. J., Yu, J., et al. (2011). Loss of msnA, a putative stress regulatory gene, in Aspergillus parasiticus and Aspergillus flavus increased production of conidia, aflatoxins and kojic acid. Toxins 3, 82-104. doi: 10.3390/toxins3010082

Chang, W., Zhan, G. M., Zheng, S., Li, Y., Li, X., Li, W., et al. (2015). Trapping toxins within lipid droplets is a resistance mechanism in fungi. Nat. Sci. Rep. 5:15133. doi: $10.1038 /$ srep 15133

Charuchinda, P., Waditee-Sirisattha, R., Kageyama, H., Yamada, D., Sirisattha, S., Tanaka, Y., et al. (2015). Caleosin from Chlorella vulgaris TISTR 8580 is salt-induced and heme-containing protein. Biosci. Biotechnol. Biochem. 79, 1119-1124. doi: 10.1080/09168451.2015.1010480

Cranmer-Byng, M. M., Liddle, D. M., De Boer, A. A., Monk, J. M., and Robinson, L. E. (2015). Proinflammatory effects of arachidonic acid in a lipopolysaccharide-induced inflammatory microenvironment in 3T3-L1 adipocytes in vitro. Appl. Physiol. Natur. Metab. 40, 142-154. doi: 10.1139/ apnm-2014-0022

Espeso, E. A., Tilburn, J., Arst, H. N. Jr., and Penalva, M. A. (1993). pH regulation is a major determinant in expression of a fungal penicillin biosynthetic gene. EMBO J. 12, 3947-3956. doi: 10.1002/j.1460-2075.1993.tb06 072.x

Fan, Y., Ortiz-Urquiza, A., Garrett, T., Pei, Y., and Keyhani, N. O. (2015). Involvement of a caleosin in lipid storage, spore dispersal, and virulence in the entomopathogenic filamentous fungus, Beauveria bassiana. Environ. Microbiol. 17, 4600-4614. doi: 10.1111/1462-2920.12990

Ferreira De Oliveira, J. M., Van Passel, M. W., Schaap, P. J., and De Graaff, L. H. (2010). Shotgun proteomics of Aspergillus niger microsomes upon D-xylose induction. Appl. Environ. Microbiol. 76, 4421-4429. doi: 10.1128/AEM.004 82-10

Field, J. A., and Sierra-Alvarez, R. (2008). Microbial degradation of chlorinated dioxins. Chemosphere 71, 1005-1018. doi: 10.1016/j.chemosphere.2007.10.039

Fountain, J. C., Koh, J., Yang, L., Pandey, M. K., Nayak, S. N., Bajaj, P., et al. (2018). Proteome analysis of Aspergillus flavus isolate-specific responses to oxidative 
stress in relationship to aflatoxin production capability. Sci. Rep. 8:3430. doi: 10.1038/s41598-018-21653-x

Fountain, J. C., Scully, B. T., Ni, X., Kemerait, R. C., Lee, R. D., Chen, Z. Y., et al. (2014). Environmental influences on maize-Aspergillus flavus interactions and aflatoxin production. Front. Microbiol. 5:40. doi: 10.3389/fmicb.2014.00040

Froissard, M., D'andrea, S., Boulard, C., and Chardot, T. (2009). Heterologous expression of AtClo1, a plant oil body protein, induces lipid accumulation in yeast. FEMS Yeast Res. 9, 428-438. doi: 10.1111/j.1567-1364.2009.00483.x

Gao, Q., and Goodman, J. M. (2015). The lipid droplet-a well-connected organelle. Front. Cell Dev. Biol. 3:49. doi: 10.3389/fcell.2015.00049

Gao, X., and Kolomiets, M. V. (2009). Host-derived lipids and oxylipins are crucial signals in modulating mycotoxin production by fungi. Toxin Rev. 28, 79-88. doi: $10.1080 / 15569540802420584$

Gilbert, M. K., Medina, A., Mack, B. M., Lebar, M. D., Rodriguez, A., Bhatnagar, D., et al. (2017). Carbon dioxide mediates the response to temperature and water activity levels in Aspergillus flavus during infection of Maize kernels. Toxins 10:E5. doi: 10.3390/toxins10010005

Goodrich-Tanrikulu, M., Mahoney, N. E., and Rodriguez, S. B. (1995). The plant growth regulator methyl jasmonate inhibits aflatoxin production by Aspergillus flavus. Microbiology 141(Pt 11), 2831-2837. doi: 10.1099/13500872-141-112831

Guzman-De-Pena, D., and Ruiz-Herrera, J. (1997). Relationship between aflatoxin biosynthesis and sporulation in Aspergillus parasiticus. Fungal Genet. Biol. 21, 198-205. doi: 10.1006/fgbi.1996.0945

Hanano, A., Alkara, M., Almousally, I., Shaban, M., Rahman, F., Hassan, M., et al. (2018a). The peroxygenase activity of the Aspergillus flavus caleosin, AfPXG, modulates the biosynthesis of aflatoxins and their trafficking and extracellular secretion via lipid droplets. Front. Microbiol. 9:158. doi: 10.3389/fmicb.2018. 00158

Hanano, A., Almousally, I., Shaban, M., and Murphy, D. J. (2018b). Arabidopsis plants exposed to dioxin result in a WRINKLED seed phenotype due to $20 \mathrm{~S}$ proteasomal degradation of WRI1. J. Exp. Bot. 69, 1781-1794. doi: 10.1093/jxb/ ery027

Hanano, A., Shaban, M., Almousally, I., and Murphy, D. J. (2018c). Identification of a dioxin-responsive oxylipin signature in roots of date palm: involvement of a 9-hydroperoxide fatty acid reductase, caleosin/peroxygenase PdPXG2. Sci. Rep. 8:13181. doi: 10.1038/s41598-018-31342-4

Hanano, A., Almousally, I., and Shaban, M. (2014a). Phytotoxicity effects and biological responses of Arabidopsis thaliana to 2,3,7,8-tetrachlorinated dibenzop-dioxin exposure. Chemosphere 104, 76-84. doi: 10.1016/j.chemosphere.2013. 10.060

Hanano, A., Ammouneh, H., Almousally, I., Alorr, A., Shaban, M., Alnaser, A. A., et al. (2014b). Traceability of polychlorinated dibenzo-dioxins/furans pollutants in soil and their ecotoxicological effects on genetics, functions and composition of bacterial community. Chemosphere 108, 326-333. doi: 10.1016/ j.chemosphere.2014.01.061

Hanano, A., Almousally, I., Shaban, M., and Blee, E. (2015). A caleosin-like protein with peroxygenase activity mediates Aspergillus flavus development, aflatoxin accumulation, and seed infection. Appl. Environ. Microbiol. 81, 6129-6144. doi: 10.1128/AEM.00867-15

Hanano, A., Almousally, I., Shaban, M., Rahman, F., Blee, E., and Murphy, D. J. (2016a). Biochemical, transcriptional, and bioinformatic analysis of lipid droplets from seeds of date palm (Phoenix dactylifera L.) and their use as potent sequestration agents against the toxic pollutant, 2,3,7,8-tetrachlorinated dibenzo-p-dioxin. Front. Plant Sci. 7:836. doi: 10.3389/fpls.2016.00836

Hanano, A., Almousally, I., Shaban, M., Rahman, F., Hassan, M., and Murphy, D. J. (2016b). Specific caleosin/peroxygenase and lipoxygenase activities are tissuedifferentially expressed in date palm (Phoenix dactylifera L.) seedlings and are further induced following exposure to the toxin 2,3,7,8-tetrachlorodibenzo-pdioxin. Front. Plant Sci. 7:2025. doi: 10.3389/fpls.2016.02025

Hanano, A., Burcklen, M., Flenet, M., Ivancich, A., Louwagie, M., Garin, J., et al. (2006). Plant seed peroxygenase is an original heme-oxygenase with an EFhand calcium binding motif. J. Biol. Chem. 281, 33140-33151. doi: 10.1074/ jbc.m605395200

Hutin, D., Tamblyn, L., Gomez, A., Grimaldi, G., Soedling, H., Cho, T., et al. (2018). Hepatocyte-specific deletion of TIPARP, a negative regulator of the aryl hydrocarbon receptor, is sufficient to increase sensitivity to dioxin-induced wasting syndrome. Toxicol. Sci. 165, 347-360. doi: 10.1093/toxsci/kfy136
IARC (2002). International Agency for Research on Cancer, AFLATOXINS, Summaries \& Evaluations. Available at: http://www.inchem.org/documents/ iarc/vol82/82-04.html

Ishida, T., Matsumoto, Y., Takeda, T., Koga, T., Ishii, Y., and Yamada, H. (2010). Distribution of 14C-2,3,7,8-tetrachlorodibenzo-p-dioxin to the brain and peripheral tissues of fetal rats and its comparison with adults. J. Toxicol. Sci. 35, 563-569. doi: 10.2131/jts.35.563

Jamme, F., Vindigni, J. D., Mechin, V., Cherifi, T., Chardot, T., and Froissard, M. (2013). Single cell synchrotron FT-IR microspectroscopy reveals a link between neutral lipid and storage carbohydrate fluxes in S. cerevisiae. PLoS One 8:e74421. doi: 10.1371/journal.pone.0074421

Katavic, V., Agrawal, G. K., Hajduch, M., Harris, S. L., and Thelen, J. J. (2006). Protein and lipid composition analysis of oil bodies from two Brassica napus cultivars. Proteomics 6, 4586-4598. doi: 10.1002/pmic.200600020

Kawamura, C., Tsujimoto, T., and Tsuge, T. (1999). Targeted disruption of a melanin biosynthesis gene affects conidial development and UV tolerance in the Japanese pear pathotype of Alternaria alternata. Mol. Plant Microbe Interact. 12, 59-63. doi: 10.1094/mpmi.1999.12.1.59

Keller, N. P., Nesbitt, C., Sarr, B., Phillips, T. D., and Burow, G. B. (1997). pH regulation of sterigmatocystin and aflatoxin biosynthesis in Aspergillus spp. Phytopathology 87, 643-648. doi: 10.1094/phyto.1997.87.6.643

Kenne, G. J., Gummadidala, P. M., Omebeyinje, M. H., Mondal, A. M., Bett, D. K., Mcfadden, S., et al. (2018). Activation of aflatoxin biosynthesis alleviates total ROS in Aspergillus parasiticus. Toxins 10:E57. doi: 10.3390/toxins10020057

Kory, N., Farese, R. V. Jr., and Walther, T. C. (2016). Targeting fat: mechanisms of protein localization to lipid droplets. Trends Cell Biol. 26, 535-546. doi: $10.1016 / j . t c b .2016 .02 .007$

Lan, H., Wu, L., Sun, R., Keller, N. P., Yang, K., Ye, L., et al. (2019). The HosA histone deacetylase regulates aflatoxin biosynthesis through direct regulation of aflatoxin cluster genes. Mol. Plant Microbe Interact. 32, 1210-1228. doi: 10.1094/MPMI-01-19-0033-R

Lawrence, B. P., and Kerkvliet, N. I. (1998). Role of altered arachidonic acid metabolism in 2,3,7, 8-tetrachlorodibenzo-p-dioxin-induced immune suppression in C57Bl/6 mice. Toxicol. Sci. 42, 13-22. doi: 10.1006/toxs.1997. 2418

Liu, H., Nie, F. H., Lin, H. Y., Ma, Y., Ju, X. H., Chen, J. J., et al. (2016). Developmental toxicity, oxidative stress, and related gene expression induced by dioxin-like PCB 126 in zebrafish (Danio rerio). Environ. Toxicol. 31, 295303. doi: 10.1002/tox.22044

Liu, H., Weisman, D., Ye, Y. B., Cui, B., Huang, Y. H., Colon-Carmona, A., et al. (2009). An oxidative stress response to polycyclic aromatic hydrocarbon exposure is rapid and complex in Arabidopsis thaliana. Plant Sci. 176, 375-382. doi: 10.1016/j.plantsci.2008.12.002

Machida, M., Asai, K., Sano, M., Tanaka, T., Kumagai, T., Terai, G., et al. (2005). Genome sequencing and analysis of Aspergillus oryzae. Nature 438, $1157-1161$.

Medina, A., Gilbert, M. K., Mack, B. M., Gr, O. B., Rodriguez, A., Bhatnagar, D., et al. (2017). Interactions between water activity and temperature on the Aspergillus flavus transcriptome and aflatoxin B1 production. Int. J. Food Microbiol. 256, 36-44. doi: 10.1016/j.ijfoodmicro.2017.05.020

Medina, A., Rodriguez, A., and Magan, N. (2014). Effect of climate change on Aspergillus flavus and aflatoxin B1 production. Front. Microbiol. 5:348. doi: 10.3389/fmicb.2014.00348

Mehl, H. L., Jaime, R., Callicott, K. A., Probst, C., Garber, N. P., Ortega-Beltran, A., et al. (2012). Aspergillus flavus diversity on crops and in the environment can be exploited to reduce aflatoxin exposure and improve health. Ann. N. Y. Acad. Sci. 1273, 7-17. doi: 10.1111/j.1749-6632.2012.06800.x

Murphy, D. J. (2012). The dynamic roles of intracellular lipid droplets: from Archaea to Mammals. Protoplasma 249, 541-585. doi: 10.1007/s00709-0110329-7

Rahman, F., Hassan, M., Hanano, A., Fitzpatrick, D. A., Mccarthy, C. G. P., and Murphy, D. J. (2018a). Evolutionary, structural and functional analysis of the caleosin/peroxygenase gene family in the Fungi. BMC Genomics 19:976. doi: 10.1186/s12864-018-5334- 1

Rahman, F., Hassan, M., Rosli, R., Almousally, I., Hanano, A., and Murphy, D. J. (2018b). Evolutionary and genomic analysis of the caleosin/peroxygenase (CLO/PXG) gene/protein families in the Viridiplantae. PLoS One 13:e0196669. doi: 10.1371/journal.pone.0196669 
Record, E., Asther, M., Moukha, S., Marion, D., Burlat, V., and Ruel, K. (1998). Localization of a phosphatidylglycerol/phosphatidylinositol transfer protein in Aspergillus oryzae. Can. J. Microbiol. 44, 945-953. doi: 10.1139/cjm-44-10-945

Reverberi, M., Ricelli, A., Zjalic, S., Fabbri, A. A., and Fanelli, C. (2010). Natural functions of mycotoxins and control of their biosynthesis in fungi. Appl. Microbiol. Biotechnol. 87, 899-911. doi: 10.1007/s00253-010-2657-5

Reverberi, M., Zjalic, S., Ricelli, A., Punelli, F., Camera, E., Fabbri, C., et al. (2008). Modulation of antioxidant defense in Aspergillus parasiticus is involved in aflatoxin biosynthesis: a role for the ApyapA gene. Eukaryot Cell 7, 988-1000. doi: 10.1128/EC.00228-07

Roze, L. V., Beaudry, R. M., Arthur, A. E., Calvo, A. M., and Linz, J. E. (2007). Aspergillus volatiles regulate aflatoxin synthesis and asexual sporulation in Aspergillus parasiticus. Appl. Environ. Microbiol. 73, 7268-7276. doi: 10.1128/ aem.00801-07

Schuldiner, M., and Bohnert, M. (2017). A different kind of love - lipid droplet contact sites. Biochim. Biophys. Acta 1862, 1188-1196. doi: 10.1016/j.bbalip. 2017.06.005

Sekiguchi, J., and Gaucher, G. M. (1977). Conidiogenesis and secondary metabolism in Penicillium urticae. Appl. Environ. Microbiol. 33, 147-158.

Shannon, G. M., Shotwell, O. L., and Kwolek, W. F. (1983). Extraction and thin layer chromatography of aflatoxin B1 in mixed feeds. J. Assoc. Off. Anal. Chem. $66,582-586$.

Shephard, G. S. (2008). Impact of mycotoxins on human health in developing countries. Food Addit. Contam. Part A Chem. Anal. Control Expo. Risk Assess. 25, 146-151. doi: 10.1080/02652030701567442

Tollot, M., Assmann, D., Becker, C., Altmuller, J., Dutheil, J. Y., Wegner, C. E., et al. (2016). The WOPR protein Ros1 is a master regulator of sporogenesis and late effector gene expression in the maize pathogen Ustilago maydis. PLoS Pathog. 12:e1005697. doi: 10.1371/journal.ppat.1005697

Trail, F., Mahanti, N., and Linz, J. (1995). Molecular biology of aflatoxin biosynthesis. Microbiology 141(Pt 4), 755-765. doi: 10.1099/13500872-1414-755

Tsujimoto, S., Ishida, T., Takeda, T., Ishii, Y., Onomura, Y., Tsukimori, K., et al. (2013). Selenium-binding protein 1: its physiological function, dependence on aryl hydrocarbon receptors, and role in wasting syndrome by $2,3,7,8$ tetrachlorodibenzo-p-dioxin. Biochim. Biophys. Acta 1830, 3616-3624. doi: 10. 1016/j.bbagen.2013.03.008

Tuomisto, J. T., Pohjanvirta, R., Unkila, M., and Tuomisto, J. (1995). 2,3,7,8Tetrachlorodibenzo-p-dioxin-induced anorexia and wasting syndrome in rats: aggravation after ventromedial hypothalamic lesion. Eur. J. Pharmacol. 293, 309-317. doi: 10.1016/s0014-2999(95)80088-3
Wakefield, L., Gadoury, D. M., Seem, R. C., Milgroom, M. G., Sun, Q., and Cadle-Davidson, L. (2011). Differential gene expression during conidiation in the grape powdery mildew pathogen, Erysiphe necator. Phytopathology 101, 839-846. doi: 10.1094/PHYTO-11-10-0295

Wang, Y., Wang, S., Nie, X., Yang, K., Xu, P., Wang, X., et al. (2019). Molecular and structural basis of nucleoside diphosphate kinase-mediated regulation of spore and sclerotia development in the fungus Aspergillus flavus. J. Biol. Chem. 294, 12415-12431. doi: 10.1074/jbc.RA119.007505

Weckbach, L. S., and Marth, E. H. (1977). Aflatoxin production by Aspergillus parasiticus in a competitive environment. Mycopathologia 62, 39-45. doi: 10 . 1007/bf00491994

WHO (2016). Dioxins and Their Effects on Human Health. Available at: http: //www.who.int/mediacentre/factsheets/fs225/en/ (accessed October 2016).

Yu, J. (2012). Current understanding on aflatoxin biosynthesis and future perspective in reducing aflatoxin contamination. Toxins 4, 1024-1057. doi: 10.3390/toxins4111024

Yu, J., Chang, P. K., Ehrlich, K. C., Cary, J. W., Bhatnagar, D., Cleveland, T. E., et al. (2004). Clustered pathway genes in aflatoxin biosynthesis. Appl. Environ. Microbiol. 70, 1253-1262. doi: 10.1128/aem.70.3.1253-1262.2004

Yu, J. H., Butchko, R. A., Fernandes, M., Keller, N. P., Leonard, T. J., and Adams, T. H. (1996). Conservation of structure and function of the aflatoxin regulatory gene aflR from Aspergillus nidulans and A. flavus. Curr. Genet. 29, 549-555. doi: $10.1007 / \mathrm{s} 002940050084$

Zeringue, H. J. Jr. (2000). Identification and effects of maize silk volatiles on cultures of Aspergillus flavus. J. Agric. Food Chem. 48, 921-925. doi: 10.1021/ jf990061k

Zhang, B., Zhang, H., Jin, J., Ni, Y., and Chen, J. (2012). PCDD/Fs-induced oxidative damage and antioxidant system responses in tobacco cell suspension cultures. Chemosphere 88, 798-805. doi: 10.1016/j.chemosphere.2012. 03.085

Conflict of Interest: The authors declare that the research was conducted in the absence of any commercial or financial relationships that could be construed as a potential conflict of interest.

Copyright (c) 2019 Hanano, Almousally and Shaban. This is an open-access article distributed under the terms of the Creative Commons Attribution License (CC BY). The use, distribution or reproduction in other forums is permitted, provided the original author(s) and the copyright owner(s) are credited and that the original publication in this journal is cited, in accordance with accepted academic practice. No use, distribution or reproduction is permitted which does not comply with these terms. 